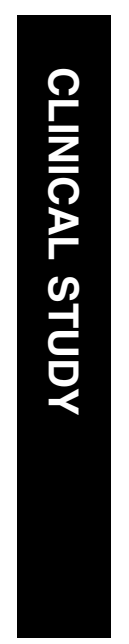

\section{Ocular involvement is associated with HLA-B51 in Adamantiades- Behçet's disease}

${ }^{1}$ Department of Ophthalmology, Campus Benjamin Franklin, Charité Universitaetsmedizin Berlin, Berlin, Germany

${ }^{2}$ Departments of Dermatology, Venereology, Allergology and Immunology, Dessau Medical Center, Dessau, Germany

\section{${ }^{3}$ Department of} Ophthalmology, Campus Virchow-Klinikum, Charité Universitaetsmedizin Berlin, Berlin, Germany

${ }^{4}$ Institute of Biometry and Clinical Epidemiology, Campus Benjamin Franklin, Charité

Universitaetsmedizin Berlin, Berlin, Germany

Correspondence: L Krause, Department of Ophthalmology,

Charité, Campus Benjamin Franklin,

Hindenburgdamm 30, Berlin 12200, Germany Tel: + 493084452331 ; Fax: + 493084454450 . E-mail: lothar.krause@ charite.de

Received: 15 November 2007

Accepted in revised form: 10 May 2008 Published online: 13 June 2008
Abstract

Purpose To evaluate the association of HLA-B51 and ocular involvement in Adamantiades-Behçet's disease.

Methods We retrospectively analysed all patients with Adamantiades-Behçet's disease examined in our Department of Ophthalmology since 1982. All patients fulfilled the criteria of the International Study Group for Behçet's disease. We included 140 patients (63 female and 77 male) with a mean follow-up of 6.4 years. Results The mean age at the first manifestation was 23 years; full disease was noted at 32 years. The mean age at the time of eye involvement was 30 years. Most of the patients were of Turkish $(n=73)$ or German $(n=34)$ origin. A total of $56 \%$ patients developed eye involvement. Forty-nine out of 76 HLA-B51-positive patients (64.5\%) and 26 out of 60 HLA-B51-negative patients $(43.3 \%$; $P=0.014)$ developed ocular involvement. Conclusion More than the half of the patients with Adamantiades-Behçet's disease evaluated in our department developed ocular involvement. There was a statistically significantly higher frequency of HLA-B51 in these patients. Eye (2009) 23, 1182-1186; doi:10.1038/eye.2008.177; published online 13 June 2008

Keywords: Adamantiades-Behçet's disease; prevalence; epidemiology; HLA-B51; uveitis

\section{Introduction}

Adamantiades-Behçet's disease (ABD) is a multisystem vasculopathy/vasculitis with the classic clinical signs of recurrent oral ulcers, genital ulcers, and uveitis. The classic signs are often accompanied by skin, arthritic, intestinal, and neurological involvement. The disease is found throughout the world, although mainly
L Krause ${ }^{1}$, A-K Köhler ${ }^{1}$, A Altenburg², N Papoutsis², CC Zouboulis², U Pleyer ${ }^{3}$, A Stroux ${ }^{4}$ and $\mathrm{MH}$ Foerster ${ }^{1}$ among individuals of Mediterranean and EastAsian descent along the 'Silk Road'.

Epidemiologic studies demonstrate a prevalence of $\mathrm{ABD}$ in the range of $0.12-420$ per 100000 inhabitants, with the highest numbers in Istanbul and Turkey and the lowest in the United States of America. The aetiology of the disease still remains unknown. ${ }^{1-6}$ Genetic factors, infectious agents and environmental pollution, immunological mechanisms, and endothelial and clotting factors have been implicated and studied intensively. Evidence for genetic predisposition might be a familial occurrence. ${ }^{7}$ A positive familial history was found in several studies and differs worldwide in the range of $2-18 \%$ with the lowest percentages in Japan and the highest in Korea and Turkey. ${ }^{8}$ In Europe, familial occurrence in ABD seems to be rare. In addition, several studies have shown an association between HLA-B51 and ABD. ${ }^{9-11}$ So far, the role of HLA$\mathrm{B} 51$ regarding the incidence of this disease or its expression is not completely understood. It was shown that HLA-B5-positive individuals from northern Europe have a lower risk to develop the disease compared with patients from the southern parts of Europe. Furthermore, it was stated that HLA-B51 is a marker for unfavourable prognosis. ${ }^{8}$ Not only the detection rates of HLA-B51 but also the association of HLA-B51 with clinical manifestations of the disease vary worldwide. Notably, ophthalmologic data for the association between ocular involvement and HLA-B51 are missing. In order to evaluate the correlation of ocular involvement and HLA-B51, we conducted this retrospective study.

\section{Materials and methods}

We retrospectively analysed data from 140 patients (63 female and 77 male) with ABD 
examined in our department between 1982 and 2006. Rheumatologists, dermatologists, or ophthalmologists sent their patients to our department in the case of ocular involvement, to screen for ocular involvement or to detect signs of ocular involvement in the past. Seventythree patients were of Turkish origin (31 female and 42 male); 34 patients were originally from Germany (20 female, 14 male); 8 patients from Lebanon; 3 patients from Italy; 3 patients from Greece; 3 patients from Morocco; 3 patients from Laos; 2 patients from Iran; 1 patient each from Cuba, Albania, Afghanistan, Jordania, Pakistan, Kosovo, Mali, Korea, Iraq, Syria, Tunis, and Serbia; and 1 patient was of African origin (Figure 1). All patients fulfilled the criteria of the International Study Group for Behçet's disease. ${ }^{12}$ The diagnostic criteria were recurrent oral aphthous ulcers accompanied by any two of the following: recurrent genital ulcerations, eye lesions, and positive pathergy test.

Patients had a mean follow-up of 6.4 years (0.5-22 years).

Age of onset, sex ratio, family history, age of ocular involvement, percentage of ocular involvement, clinical manifestations in general, type of ocular manifestations, and HLA haplotype were evaluated.

For statistical analyses, we used the SPSS (statistical package for social sciences, version 13) programme. Data are presented as median values with minimum and maximum or as mean values with SD. For confirmatory analysis concerning categorical variables, we used the $\chi^{2}$-test, or in the case of more than $25 \%$ cells with an expected size of less than 5, Fisher's exact test. For statistical comparisons with regard to ordinal data we used Mann-Whitney's U-test or Kruskal-Wallis test.

Additionally, in order to identify independent predictors for ocular involvement, multiple logistic regression analysis with forward and backward selection was performed.

\section{Results}

The mean age at the onset of the disease was 23 years (3-53 years; Figure 1). The overall male-to-female ratio was $1: 0.82$.

Age at the time of full disease was 32 years (7.4-71 years; Table 1). The duration from onset of the disease to diagnosis was 9.5 years ( $0-51$ years).

A total of $56 \%$ patients developed ocular involvement during follow-up, including $60 \%$ male and $40 \%$ female patients; $47 \%$ of the German patients, $59 \%$ of the Turkish patients, and $61 \%$ of the patients of other origins developed ocular involvement $(P=0.443)$. Ocular involvement was bilateral in $58(73 \%)$ patients and unilateral in $21(27 \%)$ patients. The mean age of first eye involvement was 29.8 years (12.5-57.8 years).

In $75 \%$ patients, appearance of oral ulcers was the onset sign, followed by arthritis and ocular involvement each in $9 \%$ patients.

The major first ocular signs of the involved eyes were panuveitis $(63 \%)$, retinal vasculitis $(14 \%)$, and iridocyclitis $(15 \%)$. Hypopyon or a papillitis were rare signs $(0.7 \%)$. The mean duration between the onset sign and the first ocular involvement was 81 months.

Table 1 Clinical characteristics

\begin{tabular}{lcc}
\hline & Results & Range \\
\hline Number of patients & 140 & \\
$\quad$ Male & 77 & \\
Female & 63 & \\
Age/disease onset (years) & 23 & $3-46$ \\
Age/full disease (years) & 32 & 7.41 \\
Age/eye involvement (years) & 29.8 & $12.5-68$ \\
Eye involvement (\%) & 56.4 & \\
Bilateral (\%) & 73.4 & \\
\hline
\end{tabular}

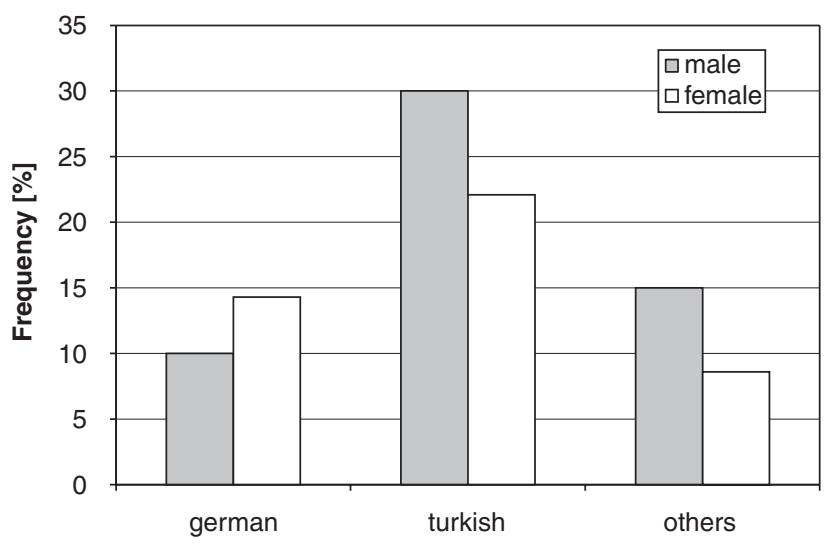

Figure 1 Patients' origin and sex ratio. 
The major second signs were genital ulcers in 34\%, ocular involvement in 19\%, oral ulcers in 19\%, and erythema nodosum in $9 \%$ of the patients. Less frequently, arthritis, folliculitis, CNS involvement, epidymiditis, or colitis were the second signs. Ocular involvement as a second sign $(n=27)$ was more frequent in Turkish $(n=18)$ than in German patients $(n=2)$.

\section{HLA-B51}

A total of 136 out of 140 included patients were tested for HLA-B51; 49 out of 76 patients tested positive for HLAB51 $(63 \%)$ developed ocular involvement (Figure 2). In contrast, out of the 60 HLA-B51-negative patients, only 26 patients $(43 \%)$ developed uveitis.

There was a statistically significantly higher frequency of HLA-B51 in patients developing ocular involvement $(P=0.014$; Figure 2$)$, as well as a significantly lower frequency of HLA-B51 positives in German (24\%) compared with Turkish $(73 \%)$ and other $(52 \%)$ patients $(P>0.0005)$.

After performing multiple logistic regression analysis with ocular involvement as the dependant and sex, age at onset of disease, HLA-B51, and nationality as the dependant variables, HLA-B51 remained the only predictor after backward and forward selection $(P=0.015$, odds ratio $=2.4)$.

\section{Familial occurrence}

The family histories were registered for 140 patients. A total of $23(16 \%)$ patients, 12 women $(52 \%)$ and 11 men $(48 \%)$, had relatives with ABD (Table 2$)$. In none of the German patients was a positive family history recorded, but 19 out of 73 (26\%) Turkish and 4 (12\%) out of the 33 other patients had a positive family history $(P=0.002)$.

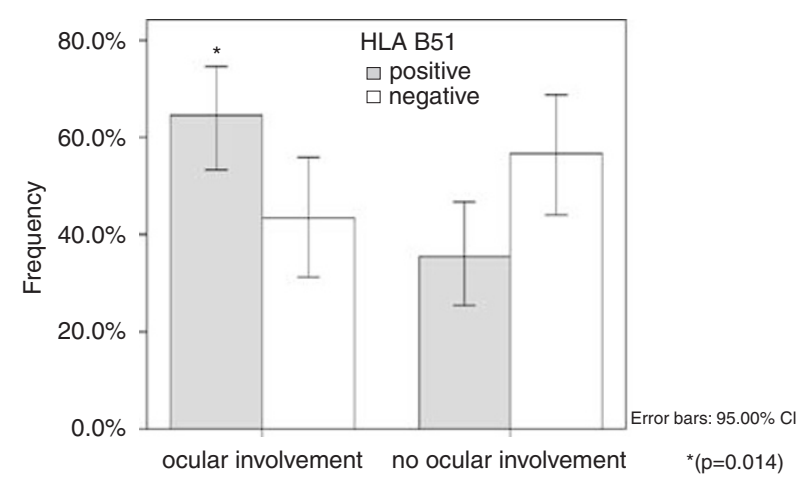

Figure 2 Eye involvement and HLA-B51.

\section{Discussion}

The aetiology of ABD is still unknown. The common involvement of specific ethnic groups, ${ }^{8}$ new data showing a similar prevalence of ethnic groups living in different parts of the world, ${ }^{6}$ distribution along the 'Silk $\operatorname{Road}^{\prime},{ }^{1}$ and association with HLA-B51 indicate a genetically determined disease with minor importance of environmental factors. So far, the role of HLA-B51 is not completely understood. The prevalence of familial ABD is in the range of $1-18 \% .{ }^{8,9,13-19}$ In a study from Turkey, the risk of disease in sisters was 11.4-52.5. ${ }^{19}$ Among different genetic markers, the class I HLA-B5 and -B51 gene on chromosome $6 \mathrm{p} 21$ is in association with ABD. ${ }^{20,21}$ The relative risk of ABD in HLA-B51-positive patients is 13.3 for Turkey, 6.7 for Japan, and 1.3 for the United States of America. ${ }^{22}$ HLA-B51 and its suballeles, B5101 and 5121, are important for antigen synthesis of $\mathrm{CD}^{+}$cytotoxic suppressor T cells. HLA-B51 and neutrophils are important for fMLP-induced superoxide production and for the pathologic distribution of $\mathrm{T}$ lymphocytes characteristic to ABD. ${ }^{23-25}$

Both HLA-B5101 and -B5102 were detected in patients with ocular involvement in ABD. ${ }^{26-28}$ Also, MICA006 (MHC class I chain related gene A) gene, which lies directly beside the HLA-B51 gene on chromosome 6, was found in ABD patients. ${ }^{29,30}$ It is unknown whether the gene product has a pathological effect or it enables an autoimmune reaction triggered by a pathogen similar to HLA-B, so that it is not detected and eliminated by the immune system. One example is the retinal $S$ antigen, a retinal protein that is found only after tissue destruction following uveitis and triggers T-cell response. ${ }^{31}$ One epitope of this protein is similar to HLA-B51 and -B27, the latter being another gene associated with uveitis. ${ }^{32,33}$ It is likely that these proteins, once released, support and feed chronic uveitis. This might be an explanation why HLA-B51 is found in patients with ocular involvement.
Table 2 Familial occurrence

\begin{tabular}{llcr}
\hline Country & Familial occurrence & $\mathrm{n}$ & $\%$ \\
\hline Germany & Negative & 34 & 100.0 \\
Turkey & Negative & $54^{*}$ & 74.0 \\
& Father & 4 & 5.5 \\
& Mother & 1 & 1.4 \\
& Brother & 7 & 9.6 \\
& Sister & 4 & 5.5 \\
& Uncle & 1 & 1.4 \\
& Grandparents & 1 & 1.4 \\
Other nations & Niece & 1 & 1.4 \\
& Negative & 29 & 87.9 \\
& Sister & 2 & 6.1 \\
& Cousin & 2 & 6.1 \\
\hline
\end{tabular}

${ }^{*} P=0.002$ 
Also, HLA-B51 seems to be associated with a severe course of the disease. ${ }^{34}$ According to this, we also detected a higher rate of posterior uveitis in HLA-B51positive patients $(P=0.038)$ in our series, whereas others did not find this correlation. ${ }^{35}$ In contrast to the data of the German registry published by Zouboulis et al, ${ }^{8}$ Kötter et $a l^{10}$ did not find any correlation of HLA-B51 and eye involvement in their study published in 2004. Reasons might be the small number of patients in the second study and a different genetic background of the German population of northeast and southwest Germany. Our data are homogeneous and, moreover, HLA-typing was done in the same laboratory. Kilmartin $e^{2} \mathrm{al}^{36}$ did not find an association of HLA-B51 with eye involvement in a series of 24 patients in the Republic of Ireland. In contrast to these results, another study by Verity et $a l^{37}$ involving a larger number of patients detected an association of HLA-B51 with ocular involvement in ABD among middle-eastern patients of Palestinian and Jordanian descent.

To evaluate the association of ABD with HLA-B51 and familial occurrence, we conducted a retrospective analysis of all patients examined in the Department of Ophthalmology between 1982 and 2006, providing an insight into the HLA-B51 distribution and familial occurrence of 140 patients included in this study. It is obvious that $\mathrm{ABD}$ is a rare disease in Germany, but with rising migration, the disease is becoming a greater cause of concern in Germany as well. ${ }^{6}$

\section{References}

1 Zouboulis CC, May T. Pathogenesis of AdamantiadesBehcet's disease. Adv Exp Med Biol 2003; 528: 161-171.

2 Yazici H, Fresko I, Yurdakul S. Behcet's syndrome: disease manifestations, management, and advances in treatment. Nat Clin Pract Rheumatol 2007; 3: 148-155.

3 Zierhut M, Mizuki N, Ohno S, Inoko H, Gül A, Onoé K et al. Immunology and functional genomics of Behcet's disease. Cell Mol Life Sci 2003; 60: 1903-1922.

4 Krause L. Adamantiades-Behcet's disease. Ophthalmologe 2005; 102: 329-334.

5 Altenburg A, Papoutsis N, Orawa H, Martus P, Krause L, Zouboulis CC. Epidemiology and clinical manifestations of Adamantiades-Behcet disease in Germany-current pathogenetic concepts and therapeutic possibilities. J Dtsch Dermatol Ges 2006; 4: 49-64; quiz 65-6.

6 Papoutsis NG, Abdel-Naser MB, Altenburg A, Orawa H, Kötter I, Krause L et al. Prevalence of Adamantiades-Becet's disease in Germany and the municipality of Berlin: results of a nationwide survey. Clin Exp Rheumatol 2006; 24: 125.

7 Fresko I, Soy M, Hamuryudan V, Yurdakul S, Yavuz S, Tümer $\mathrm{Z}$ et al. Genetic anticipation in Behcet's syndrome. Ann Rheum Dis 1998; 57: 45-48.

8 Zouboulis CC. Epidemiology of Adamantiades-Behcet's disease. Ann Med Interne (Paris) 1999; 150: 488-498.
9 Zouboulis CC, Kotter I, Djawari D, Kirch W, Kohl PK, Oschsendorf FR et al. Epidemiological features of Adamantiades-Behcet's disease in Germany and in Europe. Yonsei Med J 1997; 38: 411-422.

10 Kotter I, Vonthein R, Muller CA, Gunaydin I, Zierhut M, Stubiger N. Behcet's disease in patients of German and Turkish origin living in Germany: a comparative analysis. J Rheumatol 2004; 31: 133-139.

11 Direskeneli H. Behcet's disease: infectious aetiology, new autoantigens, and HLA-B51. Ann Rheum Dis 2001; 60: 996-1002.

12 International Study Group for Behcet's Disease. Criteria for diagnosis of Behcet's disease. Lancet 1990; 335: 1078-1080.

13 Akpolat T, Koc Y, Yeniay I et al. Familial Behcet's disease. Eur J Med 1992; 1: 391-395.

14 Arber N, Klein T, Meiner Z, Pras E, Weinberger A. Close association of HLA-B51 and B52 in Israeli patients with Behcet's syndrome. Ann Rheum Dis 1991; 50: 351-353.

15 Gurler A, Boyvat A, Tursen U. Clinical manifestations of Behcet's disease: an analysis of 2147 patients. Yonsei Med J 1997; 38: 423-427.

16 Kone-Paut I, Geisler I, Wechsler B, Ozen S, Ozdogan H, Rozenbaum $\mathrm{M}$ et al. Familial aggregation in Behcet's disease: high frequency in siblings and parents of pediatric probands. J Pediatr 1999; 135: 89-93.

17 Nishiyama M, Nakae K, Umehara T. A study of familial occurrence of Behcet's disease with and without ocular lesions. Jpn J Ophthalmol 2001; 45: 313-316.

18 Nishiyama M, Nakae K, Kuriyama T, Hashimoto M, Hsu ZN. A study among related pairs of Japanese patients with familial Behcet's disease: group comparisons by interval of disease onsets. J Rheumatol 2002; 29: 743-747.

19 Gul A, Inanc M, Ocal L, Aral O, Konice M. Familial aggregation of Behcet's disease in Turkey. Ann Rheum Dis 2000; 59: 622-625.

20 Suzuki Kurokawa M, Suzuki N. Behcet's disease. Clin Exp Med 2004; 4: 10-20.

21 Verity DH, Marr JE, Ohno S, Wallace GR, Stanford MR. Behcet's disease, the Silk Road and HLA-B51: historical and geographical perspectives. Tissue Antigens 1999; 54: 213-220.

22 Atmaca LS. Fundus changes associated with Behcet's disease. Graefes Arch Clin Exp Ophthalmol 1989; 227: 340-344.

23 Kaneko S, Suzuki N, Yamashita N, Nagafuchi H, Nakajima $\mathrm{T}$, Wakisaka $\mathrm{S}$ et al. Characterization of T cells specific for an epitope of human 60-kD heat shock protein (hsp) in patients with Behcet's disease (BD) in Japan. Clin Exp Immunol 1997; 108: 204-212.

24 Yamashita N, Kaneoka H, Kaneko S, Takeno M, Oneda K, Koizumi $\mathrm{H}$ et al. Role of gammadelta $\mathrm{T}$ lymphocytes in the development of Behcet's disease. Clin Exp Immunol 1997; 107: 241-247.

25 Yamashita N. Hyperreactivity of neutrophils and abnormal T cell homeostasis: a new insight for pathogenesis of Behcet's disease. Int Rev Immunol 1997; 14: 11-19.

26 Boyd SR, Young S, Lightman S. Immunopathology of the noninfectious posterior and intermediate uveitides. Surv Ophthalmol 2001; 46: 209-233.

27 Kera J, Mizuki N, Ota M, Katsuyama Y, Pivetti-Pezzi P, Ohno $S$ et al. Significant associations of HLA-B $* 5101$ and B*5108, and lack of association of class II alleles with Behcet's disease in Italian patients. Tissue Antigens 1999; 54: 565-571. 
28 Pirim I, Atasoy M, Ikbal M, Erdem T, Aliagaoglu C. HLA class I and class II genotyping in patients with Behcet's disease: a regional study of eastern part of Turkey. Tissue Antigens 2004; 64: 293-297.

29 Mizuki N, Ota M, Katsuyama Y, Yabuki K, Ando H, Goto K et al. Association analysis between the MIC-A and HLA-B alleles in Japanese patients with Behcet's disease. Arthritis Rheum 1999; 42: 1961-1966.

30 Yabuki K, Mizuki N, Ota M, Katsuyama Y, Palimeris G, Stavropoulos $\mathrm{C}$ et al. Association of MICA gene and HLAB 5101 with Behcet's disease in Greece. Invest Ophthalmol Vis Sci 1999; 40: 1921-1926.

31 de Smet MD, Yamamoto JH, Mochizuki M, Gery I, Singh VK, Shinohara $\mathrm{T}$ et al. Cellular immune responses of patients with uveitis to retinal antigens and their fragments. Am J Ophthalmol 1990; 110: 135-142.

32 Wildner G, Diedrichs-Mohring M, Thurau SR. Induction of arthritis and uveitis in Lewis rats by antigenic mimicry of peptides from HLA-B27 and cytokeratin. Eur J Immunol 2002; 32: 299-306.

33 Wildner G, Thurau SR. Cross-reactivity between an HLAB27-derived peptide and a retinal autoantigen peptide: a clue to major histocompatibility complex association with autoimmune disease. Eur J Immunol 1994; 24: 2579-2585.

34 Zouboulis CC, Turnbull JR, Martus P. Univariate and multivariate analyses comparing demographic, genetic, clinical, and serological risk factors for severe Adamantiades-Behçet's Disease. In: Zouboulis CC (ed). Adamantiades-Behçet's Disease. Kluwer/Plenum: London Amsterdam, 2003; 123-126.

35 Takeuchi M, Hokama H, Tsukahara R, Kezuka T, Goto H, Sakai J et al. Risk and prognostic factors of poor visual outcome in Behcet's disease with ocular involvement. Graefes Arch Clin Exp Ophthalmol 2005; 243(11): 1147-1152.

36 Kilmartin DJ, Finch A, Acheson RW. Primary association of HLA-B51 with Behçet's disease in Ireland. Br J Ophthalmol 1997; 81(8): 649-653.

37 Verity DH, Wallace GR, Vaughan RW, Kondeatis E, Madanat $\mathrm{W}$, Zureikat $\mathrm{H}$ et al. HLA and tumour necrosis factor (TNF) polymorphisms in ocular Behçet's disease. Tissue Antigens 1999; 54(3): 264-272. 